\title{
Article
}

Arq Neuropsiquiatr 2011;69(4):654-659

\section{The importance of the preoperative clinical parameters and the intraoperative electrophysiological monitoring in brachial plexus surgery}

\author{
Leandro Pretto Flores
}

\begin{abstract}
Objective: The study aims to demonstrate the impact of some preoperative clinical parameters on the functional outcome of patients sustaining brachial plexus injuries, and to trace some commentaries about the use of intraoperative monitoring techniques. Method: A retrospective study one hundred cases of brachial plexus surgery. The analysis regarding postoperative outcomes was performed by comparing the average of the final result of the surgery for each studied cohort. Results: Direct electrical stimulation was used in all patients, EMG in 59\%, SEPs in 37\% and evoked NAPs in 19\% of the cases. Patients in whom the motor function of the hand was totally or partially preserved before surgery, and those in whom surgery was delayed less than 6 months demonstrated significant $(p<0.05)$ better outcomes. Conclusion: The preoperative parameters associated to favorable outcomes in reconstruction of the brachial plexus are a good post-traumatic status of the hand and a short interval between injury and surgery.
\end{abstract}

Key words: brachial plexus, palsy, nerve surgery.

A importância dos parâmetros clínicos pré-operatórios e da monitoração eletrofisiológica intra-operatória para a cirurgia do plexo braquial

RESUMO

Objetivo: Apresentar o impacto de alguns parâmetros clínicos pré-operatórios sobre o prognóstico de pacientes com lesões traumáticas do plexo braquial e tecer comentários a respeito da monitorização eletrofisiológica intraoperatória. Método: Estudo retrospectivo de cem cirurgias de plexo braquial, incluindo apenas os casos que atingiram um tempo de seguimento em que poderia se assumir que o resultado final da cirurgia foi obtido. Resultados: Pacientes apresentando função motora da mão normal ou parcialmente preservada após o trauma, além daqueles nos quais o intervalo entre trauma e cirurgia foi menor do que de seis meses, apresentaram os melhores resultados $(p<0,05)$. Conclusão: Os parâmetros clínicos mais fortemente associados à obtenção de melhores resultados cirúrgicos são o estado neurológico pré-operatório da mão e um curto intervalo entre o trauma e a cirurgia. A estimulação elétrica simples é um método útil em casos de lesões associadas à tração; EMG e NAP são úteis para lesões infraclaviculares de nervos longos. Palavras-chave: plexo braquial, paralisia, cirurgia de nervos periféricos.

The brachial plexus is involved in 10 to $20 \%$ of all traumatic injuries of peripheral nerves ${ }^{1}$. Closed traction is the most common mechanism in adults, which is mainly caused by high-energy forces such as motorcycle accident, and trauma leads to section, contusion and/or stretch injuries of the neural elements. In addition, cervical nerve roots are frequently injured or avulsed close to or from the spinal $\operatorname{cord}^{2}$. Our previous study regarding epidemiological data of the brachial plexus 
trauma demonstrated that the incidence in the local population is 1.75 cases $/ 100,000$ inhabitants per year, and nerve root avulsions is associated to stretch injuries in $76 \%$ of the cases ${ }^{3}$.

Classification of brachial plexus lesions facilitates the interpretation of clinical findings, provides guidelines for surgical reconstruction, and gives information with regard to the prognosis of the injury. It is our opinion that optimization of the outcomes regarding brachial plexus surgery can be reach if all possible techniques are considered and adapted individually for the needs of each patient, depending on the findings of detailed preoperative studies and intraoperative monitoring.

The aim of this study is to demonstrate the results obtained from the first one hundred surgeries for traumatic brachial plexus injuries operated on by the author, defining the effect of some preoperative clinical parameters on the functional outcome of these patients, and tracing some commentaries about the lessons learned with the use of intraoperative electrophysiological monitoring during these surgeries.

\section{METHOD}

From 2004 to 2010 author performed 165 cases brachial plexus surgery. These cases included patients operated at the Hospital de Base do DF, and those from the author's private clinic. For this study, it was selected the first one hundred cases of traumatic injuries, including only those patients who reached a minimal postoperative follow-up to assume that the final outcome was obtained (i.e., to assume that a given muscle reached the maximal strength that could be obtained for each case, or the recovery of sensory protection was satisfactory). Cases that lost follow-up, and those patients in which surgery was not motivated by trauma (as tumors or compressive etiology) were excluded. Written informed consent was obtained from each participant and the study was carried out in accordance with the Declaration of Helsinki II. Our protocol of preoperative assessment of patients sustaining a brachial plexus injury is described elsewhere ${ }^{3}$.

In order to study post-ganglionic nerve injuries, different methods of intraoperative electrophysiological testing were employed, such as direct electrical stimulation, intraoperative electromyography (EMG), or evoked NAPs (Nerve Action Potentials). Electrical stimulation (Aesculap ${ }^{\circ}$, Tutinglen, Germany) was performed by testing each nerve structure proximally and distally to injury site, using single bipolar stimulator with voltages from 5 to $10 \mathrm{mV}$. The method of intraoperative EMG included stimulating the nerve structure proximally to the lesion and recording on the targeted muscle. For this purpose, a given nerve was electrically stimulated with a monopolar electrode with a square impulse (10-25
$\mathrm{mA}$, constant current, $0.2 \mathrm{~ms}, 5.5 / \mathrm{s})$. Electrically evoked NAPs were recorded using hook electrodes positioned proximally and distally to the injury site. Impulses of 0.2 msec in duration and supra-maximal strength were used (TECA, TD $20 A^{\circ}$, Pleaseantville, NY, USA), and filters were set in $2 \mathrm{~Hz}$ and $5 \mathrm{KHz}$. In any case in which some of the cited electrophysiological techniques demonstrated signs of regeneration (axonotmesis), the surgical procedure was restricted to neurolysis. On the other hand, if no muscle contraction, CMAP (compound muscular action potential) or NAPs response were detected, resection and grafting were performed.

Two intraoperative techniques were employed in order to evaluate the viability of the nerve roots (i.e., to identify intraspinal root avulsion), such as: [A] sensory evoked potentials (SEPs), by direct stimulation of the studied nerve root with hooks electrodes and recording on the contra-lateral cortex (square wave, duration of $200 \mathrm{msec}$, frequency 2 to 3 per sec; and an reference stimulation applied on the contra-lateral median nerve); and [B] direct stimulation of the long thoracic nerve (the supraclavicular segment of the nerve was suspended by silicon loops, and a 5 to $10 \mathrm{mV}$ electrical stimulus was applied, searching for signs of serratus anterior muscle contraction. If the electrical stimulus elicited a contraction, C5 nerve root was considered non-avulsed and used as donor for reconstruction of distal nerves. Details of this technique are described elsewhere ${ }^{4}$ ).

The British MRC (Medical Research Council) grading system $^{5}$ (0-5) was used to graduate the power of each muscle that was targeted in surgery. Sensory recovery was graded according to the Louisiana State University Medical Center Grading System for Sensory Function ${ }^{6}$ (0-5). For the purpose of comparing the observed outcomes associated to different cohorts, data were analyzed by determining the average of the final result of the surgery (AFRS). This method consisted in an average of all the results obtained by the patient for each function that was intended to recover with the surgery. Each motor function was graded according to the MRC system (0-5), and the sum of these scores was divided by the number of them. For example: a patient sustaining a C5 and C6 root injury and in whom the suprascapular, axilary and musculocutaneous nerve were targeted, obtained a strength MRC M3 for shoulder abduction, M2 for external rotation and MRC M4 for elbow flexion. In these case, the calculation consisted in $3+2+4 / 3=3$. Hence, the AFRS was 3. Other example: patient sustaining an infraclavicular open sharp wound with transection of the posterior cord, in which the axilary and the radial nerve were reinnervated. This patient recovered strength M4 for shoulder abduction, M4 for elbow extension, M3 for wrist extension, M2 for fingers exten- 
Table. Outcomes regarding preoperative clinical parameters in one hundred cases of brachial plexus surgery, according to the average of the final result of the surgery.

\begin{tabular}{|c|c|c|c|c|}
\hline & \multirow[b]{2}{*}{$\mathrm{n}$} & \multicolumn{2}{|c|}{ Outcomes } & \multirow[b]{2}{*}{$p$} \\
\hline & & Good & Poor & \\
\hline \multicolumn{5}{|l|}{ Age (years) } \\
\hline $10-20$ & 23 & $15(65 \%)$ & $8(35 \%)$ & 0.0874 \\
\hline $20-30$ & 35 & $24(68 \%)$ & $9(32 \%)$ & \\
\hline $30-40$ & 28 & $20(71 \%)$ & $8(29 \%)$ & \\
\hline$>40$ & 14 & $7(50 \%)$ & 7 (50\%) & \\
\hline Total & 100 & $66(66 \%)$ & $34(34 \%)$ & \\
\hline \multicolumn{5}{|l|}{ Type of injury } \\
\hline Total palsy & 31 & $14(46 \%)$ & $17(53 \%)$ & \\
\hline Normal hand function & 26 & $22(84 \%)$ & $4(16 \%)$ & $0.0021^{*}$ \\
\hline Residual hand function & 43 & $29(67 \%)$ & $14(33 \%)$ & \\
\hline Total & 100 & $65(65 \%)$ & $35(35 \%)$ & \\
\hline \multicolumn{5}{|l|}{ Site of the injury } \\
\hline Supraclavicular & 77 & $51(66 \%)$ & $26(34 \%)$ & 0.0763 \\
\hline Infraclavicular & 18 & $10(55 \%)$ & $8(45 \%)$ & \\
\hline Complex & 5 & $2(40 \%)$ & $3(60 \%)$ & \\
\hline Total & 100 & $63(63 \%)$ & $37(37 \%)$ & \\
\hline \multicolumn{5}{|l|}{ Interval trauma-surgery } \\
\hline Less than 3 months & 18 & $15(83 \%)$ & $3(17 \%)$ & $0.0013^{*}$ \\
\hline 3 to 6 months & 39 & $25(64 \%)$ & $14(26 \%)$ & \\
\hline 6 to 9 months & 31 & $17(54 \%)$ & $14(46 \%)$ & \\
\hline More than 9 months & 12 & $3(25 \%)$ & $9(75 \%)$ & \\
\hline
\end{tabular}

*Kruskal- Wallis test. Difference considered significant $(p<0.05)$.

sion, and M3 for thumb extension. The AFRS of this case was $(4+4+3+2+3 / 5=3.2)$. Those cases in which the AFRS was equal or better than 3 were considered as a good outcome. Poor outcomes were considered cases in which AFRS was inferior to 3.

Data processing was performed using commercially available statistical software (SPSS, version 16.0 for Windows, SPSS, Inc. Chicago, IL). Comparison between three or more variables was performed using the Kruskal-Wallis test. The significance level was set at 0.05 .

\section{RESULTS}

This retrospective study encompassed one hundred consecutive cases of traumatic injuries of the brachial plexus in adults, meeting the inclusion criteria described above. From the initial selected cohort, 18 patients were lost follow-up and substituted by the following patients of the whole operated series (meeting the inclusion criteria), aiming to analyze 100 consecutive cases. There were 71 males and 39 female, and the mean age of the group was 35 years old (ranging from 17-53 years old). The mean time interval from injury to surgery was 6.5 months (range 3 to 11 months) and the mean postoperative follow-up time was 32.5 months (ranging from 15 to 55 months). The mean time interval from injury to surgery was 225 days (ranging from 0 to 450 days) and the mode of the postoperative follow-up time was 21 months (ranging from 18 to 55 months).

The mechanism of injury included closed traction in 88 cases, gunshot wound in 8 cases and open sharp injuries in 14 patients. The most common cause of the accident was motorcycle falls, involved in $72 \%$ of the cases. Traffic accidents associated to car crash were observed in $10 \%$, and other causes of stretch injuries (as falling from trees, bicycles accident, or accident involving working machines) were identified in $6 \%$ of this series. Regarding the site of the injury, most of the cases demonstrated lesions located on the supraclavicular zone. Solely infraclavicular injuries and combined injuries were observed in $21 \%$ and $12 \%$, respectively.

The type of injury was classified as follows: [A] flail arm (total palsy of the affected upper limb), observed in $31 \%$; $[\mathrm{B}]$ cases sustaining proximal palsy of the arm and demonstrating normal (M5) or near normal (M4) func- 
tion of the hand (wrist, fingers and intrinsic), noted in $26 \%$; and $[C]$ cases sustaining palsy or normal function of the proximal muscles of the limb, and demonstrating some degree of compromising of the hand function, observed in $43 \%$ of this series.

One or more methods of intraoperative electrophysiological monitoring was employed in all cases: direct stimulation was used in all patients, EMG in 59\%, SEPs in $37 \%$ and evoked NAPs in $19 \%$ of the cases.

Outcomes were evaluated according to some preoperative parameters in Table. A multivariate analysis of the outcomes associated to age of the patient, site of the lesion, type of injury, and interval between trauma and surgery demonstrated that patients in whom the function of the hand was totally or partially preserved before surgery, and those in whom surgery was delayed less than 6 months demonstrated significant $(\mathrm{p}<0.05)$ better surgical results. Supraclavicular injuries (as root ruptures, root avulsions, sharp injuries or those caused by gunfire weapons) demonstrated a slight better outcome than infraclavicular injuries and complex injuries (supra and infraclavicular lesions), however the difference did not reach statistical significance. Age of the patient did not demonstrate any impact on the final outcome of this group of patient.

\section{DISCUSSION}

One of the great problems for those who intend to study protocols of brachial plexus surgery is the difficulty for comparing the surgical results from the different reported series. Comparison of outcomes is very difficult even for those who want to describe his/her own results, since patients sustaining brachial plexus injuries are different from each other ${ }^{7}$. Hence, we decided to develop a novel model for analyzing our results, simplifying the categorization of the results regarding two or more target nerves into one single data. Thus, the idea of the "Average of the Final Surgical Result" allowed us to simplify the analysis of the motor outcomes obtained from cases sustaining different types of injuries and submitted to different operative techniques. Such system to analyze surgical results has been previously proposed by Terzis and Kokalis ${ }^{7}$, in order to describe their outcomes associated to triceps reinnervation in infants.

One way to change the approach to a given problem is to modify how to define the "problem". The original classification of brachial plexus injuries included the following categories: upper trunk palsy (Erb-Duchenne Syndrome - C5 and C6), extended upper trunk palsy (Erb-Duchenne Plus Syndrome - C5, C6, C7), DejerineKlumpke Syndrome (C8, T1), and total palsy (flail arm) ${ }^{9}$. From the practical standpoint, this classification is only partially useful, as the day-by-day contact with different patients demonstrated that some cases could not be included in any of these groups. Moreover, our personal observation, supported by data from the literature ${ }^{10-12}$, suggested that the preoperative functional status of the hand is one of the most important predictors associated to brachial plexus surgery. The strength of the hand is directly related to better outcomes (i.e., a strong pre-operative wrist and finger flexion and extension is usually associated to better outcomes, and such outcomes become poorer as the hand become weaker or paralyzed). Hence, in this study the type of palsy was categorized according to the function of the hand: normal, compromised or paralyzed; and it was not a surprise to note that our good surgical results demonstrated a decreasing curve from normal (84\% of good outcomes), compromised (67\%) and total palsied (46\%), demonstrating statistical significance.

Our results also demonstrated statistical significance favoring good outcomes for those cases that underwent surgery earlier. This is not a novel idea, however until today the delay in treating patients sustaining brachial plexus injuries is one of the most complex problems faced for those who deal with peripheral nerve surgery, as most of the patients are sent to Departments specialized in brachial plexus surgery too late, compromising their functional rehabilitation. Our approach to the problem has been to employ a series of measures to divulgate the necessity of early investigation of these cases (by means of courses, discussions, etc) for orthopedics, neurologists, and neurosurgeons of our region, and currently we are receiving patients increasingly earlier.

All surgeries were monitored by some electrophysiological test, and practical lessons were learned by using these methods. First, the direct electrical stimulation is really a very useful method in brachial plexus surgery, as it allows to identify functional structures. This information can be used to: [A] test the integrity of some nerves, avoiding to injury them, or on the contrary, to use them as donors; [B] to evaluate the intraspinal integrity of nerve roots, as the case of stimulation of the long thoracic nerve; $[\mathrm{C}]$ to determine the topography of the injury site. Second, in cases of closed traction injuries, the information obtained from the intraoperative EMG were not so different from that obtained from direct stimulation. In these cases, as most of the patients demonstrated a complete rupture of the nerves (neurotmesis) and less severe degrees of lesions (as axonotmesis) were not frequently observed, the same level of confidence would be obtained from simple stimulation and EMG; moreover, the use of supra-maximal stimulation by the EMG can confuses the result, as the stimulus can spread through other routes or to reverberate on the anterior horn of the spinal cord, providing false-positive 


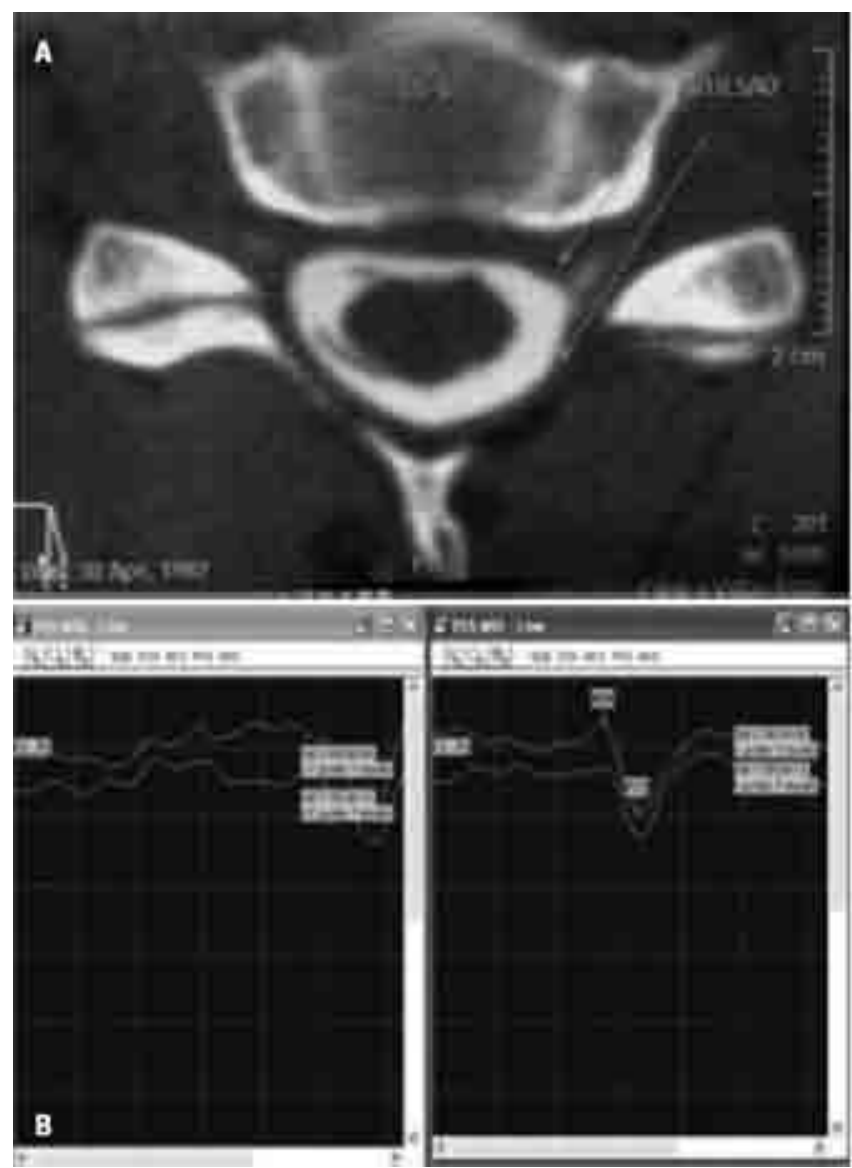

responses (this was the case of the only poor outcome associated to single neurolysis, in which intraoperative EMG was used for monitoring). Third, we consider EMG useful for cases of gunshot injuries, because in some of these cases the direct electrophysiological testing of the nerves can determine partial injuries and/or signs of preclinical recovery, avoiding to repair those structures that are spontaneously recovering.

Regarding intraoperative monitoring with $\mathrm{SEPs}^{13}$, in this series all the stimulated roots that determined evoked potentials on the contra-lateral cortex were employed as donors. We considered it as a reliable auxiliary method to check the intraspinal continuity of the nerve roots; however the use of these spinal nerves as donor should only be consider if the result of the monitoring agrees to that observed on the CT-myelogram ${ }^{14}$. In our opinion, in case of disagreement between SEPs and radiological examination, we should favor the image (Figure).

Although much has been written about the advantages of evoked NAPs ${ }^{15}$, we used this method very infrequently in our casuistic (19\%). NAP is a difficult method to be employed in restricted spaces as the supraclavicular area, however this should not be considered as an ultimate limitation for its use. Our observations based

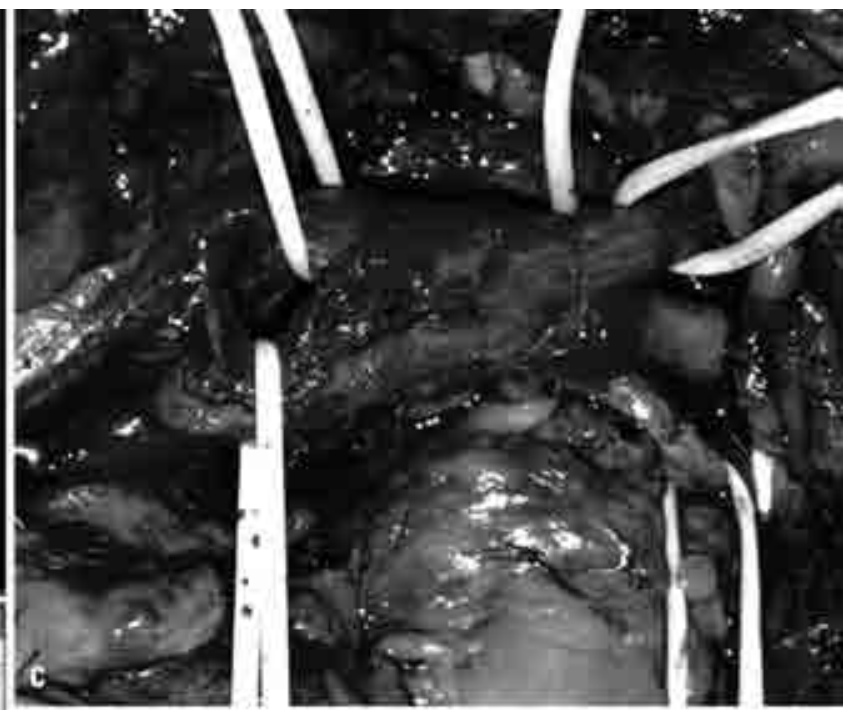

Figure. Pre and intraoperative diagnosis of nerve root avulsion. [A] CT-myelogram demonstrating avulsion of the anterior and posterior rootlets of C6. [B] Intraoperative SEPs. Left: observe that no evoked potentials can be recorded at the cortex (stimulation on the contra-lateral sixth cervical nerve). Right: a normal record from the healthy arm by stimulation on the contra-lateral median nerve (normal reference). [C] Operative photograph demonstrating avulsion of $\mathrm{C} 5$ and $\mathrm{C} 6$ nerve roots (the distal arm is to the right side of the image).

on this series suggest that the use of evoked NAPs for closed traction injuries is more restricted, for the following reasons: [A] from the practical standpoint, most of approaches to the non-avulsed spinal nerves (frequently the upper roots C5 and C6) demonstrated injuries to a site that is very close to the intervertebral foramen. The adequate area for proper placement of the tripolar stimulator hook on the spinal nerve (even those especially designed for nerve root stimulation) is usually very small or we simply cannot find it; [B] stimulation of an avulsed nerve root may evoke a action potential of low amplitude (due the integrity of the sensory axons from the dorsal root ganglion), and may evoke a falsepositive result. On the other hand, we consider evoked NAPs as a valuable intraoperative method for testing incontinuity injuries of long nerves (as ulnar, radial or median nerves) at the infraclavicular area. For these nerves, and especially in those cases in which the surgery is performed before the sixth month following the trauma, evoked NAPs can identify axonal regeneration much earlier than EMG.

In conclusion, detailed preoperative evaluation of cases sustaining a brachial plexus injury is imperative in order to determine the appropriate surgical strategy. The most important preoperative parameters for obtaining 
good outcomes are the normal or near normal post-traumatic status of the hand and a short interval between injury and surgery. Simple electrical stimulation is a very useful monitoring method for closed traction injuries; EMG and NAP are especially useful for lesions of long infraclavicular nerves.

\section{REFERENCES}

1. Mumenthaler M. Some clinical aspects of peripheral nerve lesions. Eur Neurol 1969;2:257-268.

2. Kim DH, Murovic JA, Tiel RL, Kline DG. Mechanisms of injury in operative brachial plexus lesions. Neurosurg Focus 2004;16:2.

3. Flores LP. Epidemiological study of the traumatic brachial plexus injuries in adults. Arq Neuropsiquiatr 2006;64:88-94.

4. Flores LP. Functional assessment of C -5 ventral rootlets by intraoperative electrical stimulation of the supraclavicular segment of the long thoracic nerve during brachial plexus surgery. J Neurosurg 2008;108: 533-540.

5. Bhardwaj P, Bhardwaj N. Motor grading of elbow flexion: is Medical Research Council grading good enough? J Brachial Plex Peripher Nerve Inj 2009;13:4:3.

6. Kline DG. Surgical repair of peripheral nerve injury. Muscle Nerve 1990 13:843-852.
7. Terzis JK, Kokkalis ZT. Restoration of elbow extension after primary reconstruction in obstetric brachial plexus palsy. J Pediatr Orthop 2010;30: 161-168.

8. Belzberg AJ, Dorsi MJ, Storm PB, Moriarity JL. Surgical repair of brachial plexus: a multinational survey of experienced peripheral nerve surgeons. J Neurosurg 2004;101:365-376.

9. Moran SL, Steinmann SP, Shin AY. Adult brachial plexus injuries: mechanism, patterns of injury and physical diagnosis. Hand Clin 2005;21:13-24.

10. Alton JY. Traumatic brachial plexus lesions in the adult. Indications and results. Hand Clin 1995;11:623-631.

11. Bengtson KA, Spinner RJ, Bishop AT, et al. Measuring outcomes in adult brachial plexus reconstruction. Hand Clin 2008;24:410-415.

12. Mackinnon SE, Novak CB, Myckatyn TM, Tung TH. Results of reinnervation of the biceps and brachialis muscles with a double fascicular transfer for elbow flexion. J Hand Surg [Am] 2005;30:978-985.

13. Sugioka H, Tsuyama N, Hara T, Nagano A, Tachibana S, Ochiai N. Investigation of brachial plexus injuries by intraoperative cortical somatosensory evoked potentials. Arch Orthop Traumat Surg 1982;99:143-151.

14. Carvalho GA, Nikkhan G, Matthies C, Penkert G, Samii M. Diagnosis of root avulsion in traumatic brachial plexus injuries: value of computed tomography myelography and magnetic resonance imaging. J Neurosurg 1997; 86:69-76.

15. Kline DG, Happel LT. Penfield lecture: a quarter century's experience with intraoperative action potential recording. Can J Neurol Sci 1993;20:3-10. 